\title{
Research on the Overall Logistics Service Strategy of the Publications Trading Center in CS City
}

\author{
Shijun Yuan \\ Hunan Vocational College of Modern Logistics \\ Changsha, China 410131
}

\author{
Jianhua Chen* \\ Hunan Vocational College of Modern Logistics \\ Changsha, China 410131 \\ *Corresponding Author
}

\begin{abstract}
Based on the analysis of the current situation of the logistics management in the publishing industry, this paper investigates the logistics needs of the publications dealers and potential customers, and formulates the overall logistics service strategy of the CS Publications Trading Center
\end{abstract}

Keywords—publication; logistics; strategy

\section{INTRODUCTION}

CS City Publications Trading Center was established in accordance with the requirements of relevant laws and regulations, Now and from now on is the only publication wholesale market in Hunan Province the people' $\mathrm{s}$ government of CS has given policy support to the construction project of CS publications trading center as the key project of cultural industry development in the whole city.

\section{GENERAL INTRODUCTION}

CS Publications Trading Center has a total investment of 500 million yuan, the main body Center covers an area of 56 $\mathrm{mu}$, the storage area is more than $50 \mathrm{mu}$, the ancillary service market covers an area of $80 \mathrm{mu}$. It is the only publication copyright and property exchange and distribution center of the province in accordance with the "Regulations on the management of publications market" requirements, applied by Yu Hua district government, declared by CS City Press and Publication Bureau, examined and approved by the Provincial Press and publication Bureau, recorded by the State press and publication Administration, which is the key cultural industrial base of CS city.

The center mainly sells books, periodicals, newspapers, audiovisual products, electronic publications and copyright transactions. It is a Publication trade "aircraft carrier" that integrates large-scale book markets, exhibitions, copyright trade, electronic commerce, and professional logistics distribution, equipped with direct rolling sightseeing ladder, central computer information network, composite electric power telecommunication, electronic monitoring and monitoring, indoor fire prevention and spray alarm and other advanced facilities, it has the characteristics of nationality, internationalization, individuation, digitization, networking, etc. It will become the largest publishing and software trading center in the central and southern region and the national electronic game software and copyright trading center.

\section{CURRENT SituATION AND DEVELOPMENT OF LOGISTICS MANAGEMENT IN PUBLISHING INDUSTRY}

At present, China's publishing industry is facing an unprecedented fierce competition. The pressure of competition mainly comes from the participation of domestic social funds and the involvement of foreign transnational media groups. These two new entrants have brought challenges to the publishing industry which is originally a planned economy management, and also brought opportunities for development. In the face of the rapid growth and overall development of the logistics industry in China, the publishing industry, as one of the top ten industries in China, is lagging behind in the development of logistics industry because of the traditional business model, and the logistics and information flow are relatively lagging behind. It leads to the problems of high cost, slow speed, large inventory, difficult to deal with inventory and so on. The high logistics cost, which accounts for more than a fifth of the total cost, is becoming the bottleneck restricting the profit growth of the publishing industry

The current project radiates the region book material flow is very big, also is in the front row of the whole country. CS publication transaction center construction has complied with the publishing industry development tendency need, will certainly promote and drive Hunan publishing industry and the logistics industry two-way development.

\section{INVESTIGATION ON LOGISTICS SERVICE NEEDS OF TRADING CENTER}

\section{A. Survey of the Existing Publications Logistics Industry in Hunan}

Publication logistics refers to the physical transfer from supply to demand of books, newspapers, periodicals, audiovisual products, electronic publications, etc., in the industrial chain of production, printing, processing and wholesale and retail, including transportation, storage, packaging, loading and unloading, circulation processing, distribution and information processing associated with these activities. The process of publication logistics runs through publishing houses, printing houses, batch sellers, retailers and other enterprises.

The provincial publication logistics management model is basically a decentralized management model. The logistics activities of publishing houses and publishing enterprises shal 
be undertaken by enterprises and institutions or entrusted to other enterprises by themselves. As a result of decentralized management, the scale of logistics activities of various enterprises is not large; the logistics operations are mostly mechanical equipment such as hand-assisted forklifts, handtowed trucks, etc, the operation efficiency is low and the costs are high; regional distribution mostly depends on social transport enterprises. Sometimes delays in the delivery time and so on.

\section{B. Investigation on Logistics Demand of Distributors and Potential Customers of Logistics Center Publications}

The staff used nearly 20 days, with face-to-face interviews, telephone interviews and questionnaires, investigated 50 wholesale dealers, publishing houses, publishing industry and retail enterprises, through the investigation, draw the following preliminary conclusions.

1) The current presence or interest in trading centers is dominated by wholesale dealers, foreign publishing houses and retailers, but does not mean that the general issuer will not move to the center.

In the past, only Xinhua Bookstore General Store and the General Post Office, as well as state-controlled agencies at or above the provincial level approved by the State, which had their own business sites and distribution networks. The common practice of publishing houses is to focus on research and development, even if responsible for sales, in this part will also be warehousing and transportation, distribution business bundled to a powerful printing house .CS local publishing houses are unlikely to enter the trading center.

2) Wholesale distributors in the publishing industry currently outsource logistics links are mainly transportation and out-of-town distribution.

The reason why dealers outsource transportation and distribution logistics is to reduce the cost of logistics, then to strengthen the core business, and the third is to improve and increase e the level and quality of logistics service. In the selection of third-party logistics enterprises, the first is industry and operation experience, that is, the ability to serve, the second is pay attention to brand reputation, the third is focus on network coverage, and then pay attention to lower price; in the choice of outsourcing transportation third-party logistics enterprises. The first consideration is to provide goods to the whole transportation service, the second is to maintain a longterm good partnership with the transport enterprises, and the second is to consider the total transportation cost is the least.

3) Wholesale dealer's current warehouse basically adopts the leasing way, the area is 300-1000 square meters, the site mainly concentrates in the suburb, the rental price ranges from 10 20 yuan. In the present form, many dealers will not move the warehouse immediately, but according to the survey, they are generally dissatisfied with the rented warehouse, the price is not the main reason, the key problem is that the warehouse facilities are not ideal and far from the operating surface.

4) Dealers attach most importance to direct transportation and storage costs, and management and inventory costs are excluded from logistics costs. Very few customers know the cost of logistics as a whole. Excessive inventory and slow turnover of liquidity have become the main factors to increase logistics costs. Dealers generally lack the idea that modern logistics is the "third profit source". They do not regard logistics as the key to optimize service process and strengthen market management, but put logistics activities in a subordinate position.

5) In the process of logistics operation in enterprises, dealers think that the most difficult problem to solve is the instability of service quality, followed by the runaway information, and the lack of coordination among specialized departments, the root cause is that it is difficult to find qualified logistics managers to promote the development of business.

6) Logistics management means lag behind.

In logistics management, many enterprises still stay in the paper-pen era; some enterprises are equipped with computers, but mainly used as typing. There is no system, no network, and no understanding of advanced information technologies such as communication, bar code, scanning and EDI in logistics operations.

7) With a certain concept of collaborative competition, we hope to improve the overall competitiveness through close contact, downstream business partners. Most dealers believe that logistics costs have relatively little flexibility to control costs from their own point of view, but if considered from the point of view of supply chain operation, the integration and centralized management of logistics activities scattered in every link of the supply chain can improve the efficiency of the whole supply chain and reduce the logistics cost of the whole supply chain by scale economy and professional management.

8) Logistics value-added service needs. Logistics expansion services needed now and in the future include: receiving and delivery of goods through tracking services; telephone booking to receive goods on the same day; fast and reliable services for time-sensitive products; return goods transportation services; cargo monitoring, loading and unloading, distribution, transfer; customer network online data query and online help services; upstream and downstream business partners financial position mutual check and so on.

\section{THE OVERALl LOGISTICS SERVICE STRATEGY OF CS PUBliCATIONS TRADING CENTER}

\section{A. Logistics Strategic Positioning}

Drawing lessons from the development experience of the international advanced enterprises, considering the political, economic, industry, market and other factors of our country synthetically, through repeated research and argumentation, the trading center makes the overall logistics strategic positioning of the transaction center.

We should speed up the infrastructure construction, take warehousing and distribution as the link, take the logistics information as the foundation, rely on the trading center, take the national postal network as the backing, take the integrated service as the direction, combine the marketing strategy of the 
trading center and the overall strategy of the trading center, build the Hunan publication trading logistics platform within three years, and become China the first class publication logistics value-added service center in five years.

As a logistics service center, providing integrated logistics services for publications, such as transit, handling and warehousing, distribution, freight forwarding, and in particular, improving the efficiency of multimodal transport, will enhance the competitiveness of the Centre.

As an information and communication service center, it not only provides users with market decision information and advice, but also builds a value-added service network for EDI (EDI) system

\section{B. Logistics Service Strategy Subdivision}

1) Speeding up the construction of logistics infrastructure: Speeding up the construction of integrated logistics center is the core of improving the comprehensive benefit of logistics. With the opening up of the publication distribution market and the wholesale market, and the involvement of a large amount of foreign funds, it is inevitable that the fierce competition in the publication distribution and trading market will lead to further competition. If we grasp the first opportunity, we will take the initiative. Hunan's publishing industry needs to be multi-functional, high-level, and has a strong function of distribution and a wide range of socialized logistics centers.

Actively use high-tech logistics equipment, improve logistics management technology. At the same time, we should promote computer, information technology, special vehicle, advanced loading and unloading, storage technology and so on. Balancing the dynamic balance between logistics operating costs and market expansion needs, and the special requirements of logistics customer service from a strategic perspective, is not limited to solving input-output management problems such as process reengineering, reducing costs, strengthening training, etc and he rational allocation of limited resources.

2) Warehousing and distribution as a link: Strategic planning, strategic investment and strategic technology development are important reasons for the development of logistics modernization in recent years. China Post Logistics Company should not only solve the basic logistics problems of warehousing, transportation and distribution, but also take this as a link to the dealers, starting point, to satisfy the dealer business as the basis, and form logistics integration, in order to effectively strengthen the publication trading center of the market sales competitiveness.

3) Construction of logistics information pillar: Logistics information system is the realization means of integrated logistics thought and the mainstay of modern logistics operation. Without advanced information system, enterprises will not be able to manage cost effectively, provide excellent customer service and obtain high performance of logistics operation. In order to maintain competitiveness, enterprises must extend the role of information infrastructure to requirements planning, management control, decision analysis and so on, and combine the characteristics of information availability, accuracy, timeliness, flexibility, and change, as well as the connection with the channel members. The professional logistics solution uses the following management information system architecture:

4) Based on the trading center: The functions of the trading center will be innovatively and revolutionized in accordance with the requirements of integrated logistics services. In making logistics decisions, the logistics system should be organically integrated with the overall strategy of the trading center. The logistics strategy should closely revolve around the overall strategy of the trading center and realize the goal of becoming the logistics service center, the business center, the information and communication service center, the modern industry center, and the logistics service center, based on this, it is able to develop long.

5) Constructing integrated logistics strategy: Only when any enterprise forms a supply chain with other enterprises can it obtain the initiative of competition. The integrated logistics not only improves the level of customer service, but also reduces the total cost of logistics, and then improves the market competitiveness. The integration of internal logistics in China Post system lays the foundation for cooperation between upstream and downstream enterprises in the supply chain to form an integrated supply chain. In order to construct the integration of logistics strategy, it is necessary to make the logistics activities of many publications distributors more intensive through the strategic alliance of logistics, gradually reduce the intermediate links of circulation, gradually reduce the repeated transportation, and reduce the logistics cost of supply chain, participate in competition with the overall advantage of supply chain. From the social benefit point of view, due to the overall planning, unified implementation, reduce the duplication of social logistics process.

6) Improving service quality and establishing good reputation: Quality is the life of an enterprise and an important factor for its sustainable development. Business reputation is a valuable intangible asset of an enterprise. Enterprises should firmly establish the management concept of "customer first", establish a set of strict business rules and systems, and pay special attention to establishing the business reputation while grasping the internal mechanism management and improving the service quality, maintain established service brand.

\section{CONCLUSION}

On the basis of deeply analyzing the present situation of the logistics development of the publication industry and investigating the development of the publication logistics in the radiation area of the project, the construction of the CS publication trading center project, the position of the logistics strategy of the CS publication trading center is clarified. The logistics development strategy is put forward from the aspects of logistics infrastructure, warehousing and distribution system, 
information technology and information platform, integrated logistics service, logistics service quality and so on, in order to promote the sustainable development of the project construction and operation.

\section{REFERENCES}

[1] Dong Qianli, Research on third Party Logistics Strategy based on supply chain Management. Chinese soft science. 2000, Issue 10.

[2] $\mathrm{Hu}$ Tao, Under the background of contemporary society, the development strategy innovation scheme of logistics and economic management. Economic Research Guide. 2017, Issue 13.

[3] Wang Lei. Research on Logistics Economic Management Mode, Strategic significance and Development Countermeasures [J]. Monthly price journal. 2014(08). 